\section{Commentary: Right gastroepiploic artery versus right internal thoracic artery: Backing the wrong horse}

\author{
Chaim Locker, MD
}

In this issue of the Journal, an interesting study from South Korea is presented, comparing 10-year graft occlusion rate and long-term outcomes in 548 patients operated upon from 2000 to 2008 with the use of of-pump coronary artery bypass grafting (OPCAB) and total arterial revascularization for multivessel coronary disease using composite-T grafting with the right gastroepiploic artery (RGEA) $(\mathrm{n}=389)$ or right internal thoracic artery (RITA) $(n=159)$ as the second free graft from the side of the left internal thoracic artery (LITA). Propensity score matching yielded 152 pairs of patients. There were no statistical differences in patency rates and clinical outcomes over 10year follow-up between the matched groups. ${ }^{1}$

The authors should be commended for this study and for their motivation to provide complete follow-up over 10 years of the novel evaluation of 10-year patency of RGEA graft as composite-T compared with RITA. Notably, the authors represent a "center of excellence" in CABG and the results of this study (as many other observational reports on "niche" techniques) cannot always be applied everywhere. Indeed, this group contributed during the last 2 decades numerous publications on various OPCAB with composite-T strategies.

Historically, the superior outcomes with the internal thoracic artery (ITA) and the lack of appropriate coronary bypass conduits in some patients promoted the search for alternative arterial bypass conduits. In 1987, Pym and

From the Department of Cardiovascular Surgery, Mayo Clinic, Rochester, Minn. Disclosures: The author reported no conflicts of interest.

The Journal policy requires editors and reviewers to disclose conflicts of interest and to decline handling or reviewing manuscripts for which they may have a conflict of interest. The editors and reviewers of this article have no conflicts of interest

Received for publication June 8, 2020; revisions received June 8, 2020; accepted for publication June 12, 2020; available ahead of print June 26, 2020.

Address for reprints: Chaim Locker, MD, Department of Cardiovascular Surgery, Mayo Clinic, 200 First St SW, Rochester, MN 55905 (E-mail: lekerlocker. chaim@mayo.edu).

J Thorac Cardiovasc Surg 2022;163:1346-8

$0022-5223 / \$ 36.00$

Copyright (c) 2020 by The American Association for Thoracic Surgery

https://doi.org/10.1016/j.jtcvs.2020.06.039

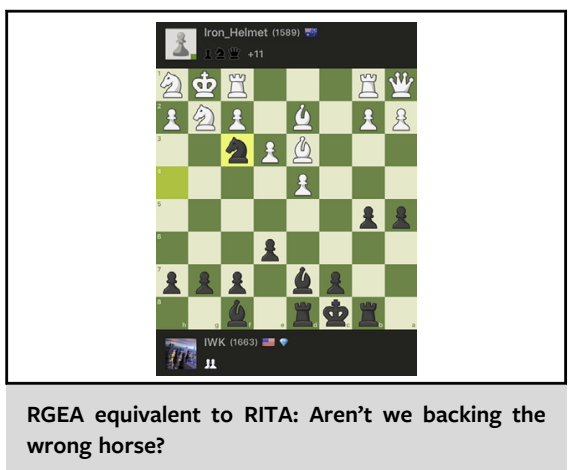

CENTRAL MESSAGE

RGEA vs RITA as the second arterial limb graft in OPCAB LITA composite-T configuration: are they really equivalent? It's time for randomized controlled studies to answer this and many other questions.

colleagues $^{2}$ reported the use of the gastroepiploic artery (GEA) as in situ conduit to the right coronary artery (RCA) and posterior circumflex branches. In their publication, they concluded that RGEA is not only an alternative conduit for absent or unsuitable conventional conduits, but in addition to the use of bilateral ITAs, it adds a third arterial coronary bypass graft to the cardiac surgeon's armamentarium. Later on, many surgeons have used the GEA as in situ or free bypass graft, trying to extend its use to more proximal coronary targets. ${ }^{3}$ Some have reported excellent mid- and long-term outcomes during the following years. ${ }^{4-6}$ Nonetheless, in current guideline recommendations for conduit use during $\mathrm{CABG}$, the only available recommendation is from the 2016 Society of Thoracic Surgeons guidelines: "The RGEA may be considered in patients with poor conduit options or as an adjunct to more complete arterial revascularization" (Class IIb, Level of Evidence B). No recommendations were provided by the 2011 American College of Cardiology Foundation/American Heart Association or the 2014 European Society of Cardiology/European Association for Cardio-Thoracic Surgery guidelines.

Although being somewhat similar macroscopically to the ITA, several important distinctions have been encountered during the following years between the 2 conduits. The relative complexity of GEA harvest, the reported postoperative 
complications (although mostly anecdotal), ${ }^{8}$ the notion of increased patient's postoperative length of stay, and some biological and functional phenomena related to the GEA (string sign), have tempered the enthusiasm of its general acceptance as a bypass conduit.

In their current paper, the authors claim that by their longterm experience, total arterial revascularization using RGEA composite grafts showed comparable results with using RITA composite grafts in terms of 10-year occlusion rates and long-term clinical outcomes up to 15 years postoperatively. This statement should be carefully examined:

Composite-T with the use of 2 arteries is a very risky operation with regards to competitive flows in the native coronaries. Glineur and colleagues ${ }^{9}$ recently showed that fractional flow reserve (FFR) $<0.78$ in the bypassed coronaries is crucial to prevent occlusion of anastomoses with arterial grafts overall, and specifically, FFR $<0.82$ is required with sequential grafting in a composite-T configuration. The current study ${ }^{1}$ included patients who underwent CABG without adopting the FFR measurement for revascularization strategies. All of the diseased left coronary territories that had $\geq 70 \%$ diameter stenosis and the right coronary territories with $\geq 90 \%$ stenosis were revascularized using the RITA and RGEA as composite grafts, respectively. Hence, the application of these criteria to the surgical technique must have been "selective," as not all patients with coronary disease present with those degrees of stenoses, and obviously the degree of angiographic coronary stenosis is in no correlation with FFR. Of note, the secondlimb conduit (RITA vs RGEA) was chosen regardless of the degree of target vessel stenosis.

The second important issue in dealing with RGEA is its frequent tendency to spasm and the more frequent prevalence of atherosclerosis. In my surgical experience, these phenomena were more prevalent with RGEA even compared with the radial artery, where no more than a handful of those dismal findings occurred with thousands of skeletonized ITA harvests. Claiming that RGEA is comparable with ITA is futile and contradicts histologic, functional, angiographic, and transit-time flow characteristics reported in literature. ${ }^{10,11}$ The RGEA is a splanchnic artery with increased tendency to spasm and to develop atherosclerosis, similar to limb arteries (eg, the radial artery). The superior endothelial function of the ITA may reflect the fact that this somatic artery is usually free from atherosclerosis whereas other types of arteries (splanchnic and limb) are much more involved with atherosclerosis, diminishing endothelial function. Splanchnic and limb arteries are prone to spasm due to greater contractility and require aggressive pharmacologic treatment. ${ }^{12}$ Indeed, the authors state that their previous studies discovered that atherosclerosis $(6.5 \%)$ and spasm of the RGEA ( $4.5 \%$ ) occurred in a total of $11 \%$ of RGEA cases-more than 1 of 10 patients! Another study from this group showed that skeletonized RGEA composite grafts with regular intraoperative flow measurements had comparable early results and patency rates with RITA composite grafts. ${ }^{13}$ Of note, there has been no change to their very efficient antispasmodic treatment of the RGEA graft during this time period.

As the authors report that RGEA was used much more frequently during the second part of the study (after publishing their 5-year results) and RITA was used much more frequently at the earlier stages of the study and substantially less thereafter, aren't we looking at evolution of treatments and somehow biased results? Another 2 concerns that might have impacted the results is the significant difference in rate of distal anastomoses per patient $(P=.03)$, with significantly more performed in the RGEA group, and the significant difference in the average number of anastomoses per patient using the second limb conduit; 2.0 for RGEA and only 1.7 for RITA $(P=.001)$. Is this implying that more incomplete revascularization occurred with the RITA group? This has been previously shown to be of vast importance to clinical outcomes. If this was a consequence of the skeletonized RITA conduits harvested shorter than RGEA conduits, patients who received RITA composite graft occasionally needed other conduits for complete revascularization. However, since patients who needed other conduits for complete revascularization were excluded from the study, does it imply that the RITA group did not consist of consecutive patients but only of those in whom all targets were reached for complete arterial revascularization? In another recent study, the "extended SAVE the RITA trial,", this group reported on their 5-year results comparing LITA composite-T with the saphenous vein graft (SVG) versus RITA as the second limb graft. In this study, a third SVG limb conduit to lengthen the second limb graft of the RITA was required in 39 of 112 patients to gain complete revascularization. First, this answers the aforementioned question and raises some additional questions; why a skeletonized RITA is not reaching in a composite-T configuration to the RCA territory to gain complete full arterial revascularization? In our experience, as well as the experience of many others, the skeletonized RITA should comfortably reach the RCA in most of those composite-T configurations. In addition, in that somewhat-weird configuration of SVG added as extension to the second limb of the RITA, what are we assessing, outcomes with the SVG or the RITA? Is this arterial-venous configuration worthwhile? Taking a risk of compromising the RITA limb graft to perform another distal anastomosis with the extension of a vein graft? Wouldn't it be safer to use it as a separate graft to the RCA? The same questions apply to this group's other recent paper. ${ }^{15}$

Finally, and back to the current study, is it justified to perform a laparotomy and open the peritoneum to harvest the RGEA, when it's becoming clear, by accumulating studies, that the skeletonized harvest technique of the 
RITA lowers the risk of sternal wound infection similar to 1 pedicled LITA? ${ }^{16}$ Indeed, in the current report, there was no apparent increase in sternal infection rate with the additional skeletonized harvest of the RITA. The chest is already open, and within 20 to 30 minutes, a skeletonized RITA can be harvested resulting in significant additional surgical versatility (in situ vs free graft off the LITA or the aorta), with the top conduit available. The concern of wound infection in greater-risk patients, eg, those with diabetes, with BITA harvest is not mitigated by the offered surgical technique (LITA + RGEA). Abdominal wound infection in a female patient with morbid obesity and diabetes with uncontrolled HGBA1C is not less fearful than a sternal infection.

The RGEA could probably serve and should be in a coronary surgeon's armamentarium as a third or fourth arterial graft conduit material, since it has been shown that comparing the use of 2 versus 3 arterial grafts for CABG, the use of 3 arterial conduits was associated with a statistically significant survival benefit at long-term follow-up. These findings support the concept that complete revascularization and extensive use of arterial grafts should be the new gold standard in current coronary surgery practice. $^{17}$

Overall, the surgical results of performing OPCAB surgery with those 2 arterial free conduits in a composite-T configuration are superb and exemplary, and the authors should be commended for this and for their persistent diligence to discover the most effective composite- $T$ strategy in CABG. The capability of performing all those highly technically demanding configurations with the OPCAB technique is definitely unique and raises the question why centers of excellence like this are not encouraged and supported by the surgical societies to conduct more well-designed randomized controlled trials (even in single centers) that would contribute significantly more to our understanding and knowledge in coronary surgery.

\section{References}

1. Kim M-S, Hwang HY, Ree K, Kim K-B. Right gastroepiploic artery versus right internal thoracic artery composite grafts: 10-year patency and long-term outcomes. J Thorac Cardiovasc Surg. 2022;163:1333-43.e1.

2. Pym J, Brown PM, Charrette EJP, Parker JO, West RO. Gastroepiploic-coronary anastomosis: a viable alternative bypass graft. J Thorac Cardiovasc Surg. 1987; 94:256-9.

3. Lytle BW, Cosgrove DM, Ratliff NB, Loop FD. Coronary artery bypass grafting with the right gastroepiploic artery. J Thorac Cardiovasc Surg. 1989;97:826-31.

4. Suma H, Wanibuchi Y, Terada Y, Fukuda S, Takayama T, Fokuda S, et al. The right gastroepiploic artery graft. J Thorac Cardiovasc Surg. 1993;105:615-23.

5. Suma H, Isomura T, Horii T, Sato T. Late angiographic result of using the right gastroepiploic artery as a graft. J Thorac Cardiovasc Surg. 2000;120:496-8.

6. Tavilla G, Bruggemans EF, Putter H. Twenty-year outcomes of coronary artery bypass grafting utilizing 3 in situ arterial grafts. J Thorac Cardiovasc Surg. 2019;157:2228-36.

7. Head SJ, Milojevic M, Taggart DP, Puskas JD. Current practice of state-of-the-art surgical coronary revascularization. Circulation. 2017;136:1331-45.

8. Manetta F, Moores DWO, Bennet EV, Edwards NM. Intrapericardial herniation of the stomach after use of the right gastroepiploic artery for coronary artery bypass grafting. J Thorac Cardiovasc Surg. 1998;115:479-80.

9. Glineur D, Grau JB, Etienne PY, Benedetto U, Fortier JH, Papadatos S, et al. Impact of preoperative fractional flow reserve on arterial bypass graft anastomotic function: the IMPAG trial. Eur Heart J. 2019;40:2421-8.

10. Kim K-B, Cho KR, Choi JS, Lee HJ. Right gastroepiploic artery for revascularization of the right coronary territory in off-pump total arterial revascularization: strategies to improve patency. Ann Thorac Surg. 2006;81:2135-41.

11. Takami Y, Tajima K, Terazawa S, Okada N, Fujii K, Sakai. Transit-time flow characteristics of in situ right gastroepiploic arterial grafts in coronary artery bypass grafting. J Thorac Cardiovasc Surg. 2009;138:669-73.

12. He GW. Arterial grafts: clinical classification and pharmacological management. Ann Cardiothorac Surg. 2013;2:507-18.

13. Cho KR, Hwang HY, Kim JS, Jeong DS, Kim KB. Comparison of right internal thoracic artery Y grafts anastomosed to the left internal thoracic artery. Ann Thorac Surg. 2010;90:744-52.

14. Kim MS, Hwang HY, Kim JS, Oh SJ, Jang MJ, Kim KB. Saphenous vein versus right internal thoracic artery as a Y-composite graft: five-year angiographic and clinical results of a randomized trial. J Thorac Cardiovasc Surg. 2018;156:1424-33.

15. Hwang HY, Lee Y, Sohn SH, Choi JW, Kim KB. Equivalent 10-year angiographic and long-term clinical outcomes with saphenous vein composite grafts and arterial composite grafts. J Thorac Cardiovasc Surg. April 8, 2020 [Epub ahead of print].

16. Benedetto U, Altman DG, Gerry S, Gray A, Lees B, Pawlaczyk R, on behalf of the Arterial Revascularization Trial investigators. Pedicled and skeletonized single and bilateral internal thoracic artery grafts and the incidence of sternal wound complications: insights from the arterial revascularization trial. J Thorac Cardiovasc Surg. 2016;152:270-6.

17. Gaudino M, Puskas JD, Di Franco A, Ohmes LB, Iannaccone M, Barbero U. Three arterial grafts improve late survival: a meta-analysis of propensitymatched studies. Circulation. 2017;135:1036-44. 